Received Date : 16-Nov-2014

Revised Date : 26-Jan-2015

Accepted Date : 30-Jan-2015

Article type : Resource Article

\title{
DNA barcoding and mini-barcoding as a powerful tool for feather mite studies
}

\author{
Jorge Doña $^{1}$, Javier Diaz-Real ${ }^{1,2}$, Sergey Mironov ${ }^{3}$, Pilar Bazaga ${ }^{1}$, David Serrano ${ }^{4}$ and Roger Jovani ${ }^{1}$ \\ ${ }^{1}$ Department of Evolutionary Ecology, Estación Biológica de Doñana (CSIC), Avda, Americo Vespucio s/n, Sevilla, Spain \\ ${ }^{2}$ Current address: Departamento de Ecoloxía e Bioloxía Animal, Universidade de Vigo, Vigo, Spain
}

${ }^{3}$ Zoological Institute, Russian Academy of Sciences, Universitetskaya Embankment 1, Saint Petersburg, Russia

${ }^{4}$ Department of Conservation Biology, Estación Biológica de Doñana (CSIC), Avda, Americo Vespucio s/n, Sevilla, Spain

*Corresponding author: Roger Jovani ; e-mail: jovani@ebd.csic.es

\begin{abstract}
Feather mites (Astigmata: Analgoidea, Pterolichoidea) are among the most abundantand commonly occurring bird ectosymbionts. Basic questions on the ecology and evolution of feather mites remain unanswered because feather mite species identification is often only possible for adult males and it is laborious even for specialised taxonomists, thus precluding large-scale identifications. Here, we This article has been accepted for publication and undergone full peer review but has not been through the copyediting, typesetting, pagination and proofreading process, which may lead to differences between this version and the Version of Record. Please cite this article as doi:

$10.1111 / 1755-0998.12384$
\end{abstract}

This article is protected by copyright. All rights reserved. 
tested DNA barcoding as a useful molecular tool to identify feather mites from passerine birds. 361 specimens of 72 species of feather mites from 68 species of European passerine birds from Russia and Spain were barcoded. The accuracy of barcoding and mini-barcoding was tested. Moreover, threshold choice (a controversial issue in barcoding studies) was also explored in a new way, by calculating through simulations the effect of sampling effort (in species number and species composition) on threshold calculations. We found one $200 \mathrm{bp}$ mini-barcode region that showed the same accuracy as the full-length barcode (602 bp) and was surrounded by conserved regions potentially useful for group-specific degenerate primers. Species identification accuracy was perfect (100\%) but decreased when singletons or species of the Proctophyllodes pinnatus group were included. In fact, barcoding confirmed previous taxonomic issues within the Proctophyllodes pinnatus group. Following an integrative taxonomy approach, we compared our barcode study with previous taxonomic knowledge on feather mites, discovering three new putative cryptic species and validating three previous morphologically different (but still undescribed) new species.

Keywords: barcode threshold, cryptic species, host-symbiont interactions, mtDNA, COI, mini-barcoding, DNA barcoding.

\section{Introduction}

Feather mites (Acari: Astigmata: Analgoidea, Pterolichoidea) are among the most abundant ectosymbionts living on birds (Gaud \& Atyeo 1996; Proctor \& Owens 2000; Proctor 2003). Among them, plumicolous mites are those living permanently on the feather surfaces of birds (Proctor 2003). In Europe alone, about 130 species of plumicolous feather mites (from 31 genera and 9 families) have been described on passerines, and a number of species have yet to be described (Mironov 1996; Mironov pers. obs).

Feather mites are present in almost all avian groups. However, there are many questions surrounding feather mite evolutionary ecology that remain unanswered (Proctor \& Owens 2000; Proctor 2003). For example, it is still debated whether the nature of bird/feather mite relationships is This article is protected by copyright. All rights reserved. 
parasitic, commensalistic or even mutualistic (Blanco et al. 2001; Figuerola et al. 2003; Galván et al. 2012). This controversy may stem from the fact that questions on feather mite ecology have been traditionally addressed by mainly correlating the combined abundance and prevalence of different mite species with host traits (e.g. Galván et al. 2012). However, we now know that the abundance of feather mites is not only shaped by host traits (e.g. body size, Galván et al. 2012, size of the uropygial gland, Galván \& Sanz 2006), but also by the species composition of feather mites living on a bird (Fernández-González et al. 2012), or differently affecting feather mite species or even by environmental factors (Dubinin 1951; Fernández-González et al. 2012; Meléndez et al. 2014). Thus, it is clear that a greater knowledge of the feather mite community living on each bird species and on each bird individual would accelerate our understanding of the evolutionary ecology of this interaction.

This approach has rarely been addressed because feather mite species identification is a difficult task; females of some taxa and immature stages of many families are often indistinguishable, and even for males, accurate identification requires advanced taxonomic skills. Moreover, in some groups of closely related species (e.g. the pinnatus species group from the genus Proctophyllodes), it is extremely difficult to identify single individuals based on morphological characters (Mironov pers. obs.). In this scenario, an accurate molecular tool for species identification would be highly valuable. In similar ecological systems, these problems have been successfully addressed by combining morphological and DNA barcoding approaches (i.e., integrative taxonomy approach), which has also been proposed as a powerful framework for species discovery and identification (Besansky et al. 2003; Smith et al. 2006; Hajibabaei et al. 2007; Schlick-Steiner et al. 2010).

On the other hand, species identifications based on barcoding do not work equally well in all groups, thus requiring a prior test of effectiveness before application to specific taxa (Moritz \& Cicero 2004; Virgilio et al. 2012; Collins \& Cruickshank 2013). This test requires an extensive

This article is protected by copyright. All rights reserved. 
barcoding library, which is not available for feather mites where only a few species (ca. $20 \mathrm{sp}$ ) have been barcoded (Ratnasingham \& Hebert 2007; Dabert et al. 2008; Dabert et al. 2011; Jinbo et al. 2011; Glowska et al. 2014). However, the efficacy of barcoding has never been tested for feather mites.

DNA barcoding is based on amplifying and sequencing DNA regions that are informative at the species level. For several animal groups the mitochondrial 648 bp region of the cytochrome oxidase subunit 1 (COI) gene has been demonstrated as a useful barcode (Hebert et al. 2003; Savolainen et al. 2005; Hajibabaei et al. 2007). It has also proven effective in complex scenarios, even revealing cryptic species (Hebert et al. 2004). Here we provide the largest library of DNA barcodes currently available for feather mites covering the majority of European passerine species, and we test the accuracy of the method. Moreover, we explored other issues around barcoding of feather mites relevant to their extended usability and confidence in addressing issues of molecular systematics:

(1) First, DNA barcodes of typical size (more than $600 \mathrm{bp}$ ) may be difficult to obtain with degraded DNA (e.g. museum specimens, dietary research, etc.), or may suffer technological restrictions. For instance, the more accurate and informative massive parallel sequencing technologies are currently limited to short DNA fragments. In these conditions, mini-barcodes have proven to be very successful (Sundquist et al. 2007); so we identified potential mini-barcodes for feather mites and explored their efficacy.

(2) The use of thresholds to differentiate species has been repeatedly discussed in the DNA barcoding literature, finding that no single threshold is optimal for all species (Puillandre et al. 2012; Virgilio et al. 2012; Collins \& Cruickshank 2013). Moreover, the accuracy of a thresholdbased approach critically depends upon the level of overlap between intra- and interspecific variation across a phylogeny (Meyer \& Paulay 2005). Also, it is known that the overlap is considerably greater when a larger proportion of closely related taxa are included, and that

This article is protected by copyright. All rights reserved. 
barcoding may perform poorly in incompletely sampled groups (Moritz \& Cicero 2004;

Ratnasingham \& Hebert 2007). Therefore, here we simulated the effect of library size (number of species) and species composition in the sample upon threshold calculation to test the robustness of our results against sampling issues.

(3) Finally, we tested the congruence of the barcode library of feather mites presented here with the previous taxonomic studies of feather mites. For this purpose, we followed an integrative taxonomy approach where we combined morphological identifications, automated procedures for primary species delimitation (ABGD) and Bayesian phylogenetic analyses (Huelsenbeck et al. 2001; Puillandre et al. 2012).

\section{Material and Methods}

\section{Sampling}

Feather mite specimens were collected during 2011-2013 from live birds captured with mist nets in different localities of Spain and Russia (Suppl. Table S1). Mites were manually collected from the feathers using a flattened preparation needle or a cotton swab impregnated with ethanol and preserved at $-20^{\circ} \mathrm{C}$ in tubes with $96 \%$ ethanol. When possible, mite samples were taken from different geographical populations and from different host species, and one to five individuals from each putative mite species were sequenced (see below). After DNA isolation, mites were mounted on slides in Faure medium according to standard techniques for small mites (Krantz \& Walter 2009) and then identified by S.M. under a Zeiss AX10 light microscope. A total of 361 specimens were identified based on morphological characters according to world revisions of the genera Proctophyllodes (Atyeo \& Braasch 1966) and Trouessartia (Santana 1976) and other corresponding taxonomic publications. The genus Proctophyllodes is the most species-rich genus (161 species) among feather mites, and the above mentioned controversial pinnatus group is the most speciose within the genus, currently including 37 species (Mironov 2012). Mites of this group are very uniform morphologically and differentiation of closely related species is mainly based on male characteristics. Since morphological overlaps between species of this group have never been This article is protected by copyright. All rights reserved. 
specifically studied, identification of species based on single specimens is often difficult. In this context, it is also possible that phylogenetically distant avian species described as hosts of presumably the same mite species actually harbour separate cryptic species. All mounted specimens were preserved at the Estación Biológica de Doñana (Spanish National Research Council, CSIC, Seville, Spain) with accession numbers (EBD1201ART- EBD1561ART).

\section{DNA isolation, amplification and sequencing}

Genomic DNA was extracted using HotSHOT (Truett et al. 2000). After extraction, exoskeletons were separated from the extraction volume and stored in $96 \%$ ethanol. A segment of approximately 650 bp of the COI region was amplified by PCR with degenerate primers bcdF05 (5 -TTTTCTACH AAYCATAAAGATATTGC-3`) and bcdR04 (5`-TATAAACYTCDGGATGNCCAAAAAA-3`) (Dabert et al. 2008). PCRs were carried out in $20 \mu 1$ reaction volumes containing $1 \mathrm{x}\left(\mathrm{NH}_{4}\right)_{2} \mathrm{SO}_{4}$ reaction buffer (Bioline), $2.5 \mathrm{~mm} \mathrm{MgCl} 2,1 \mathrm{x}$ BSA, $0.25 \mathrm{~mm}$ DNTPs, $2 \mu \mathrm{m}$ of each primer, $1.25 \mathrm{U}$ BIOTAQ $^{\mathrm{TM}}$ (Bioline) and $7 \mu$ of DNA template. The reaction followed a touchdown PCR profile: $95^{\circ} \mathrm{C}$ for $3 \mathrm{~min}, 20$ cycles of $95^{\circ} \mathrm{C}$ for $1 \mathrm{~min}, 55^{\circ} \mathrm{C}$ for $30 \mathrm{~s}$ with a decrease of $0.5^{\circ} \mathrm{C}$ every cycle, $72^{\circ} \mathrm{C}$ for $1 \mathrm{~min}$, and 20 cycles of $95^{\circ} \mathrm{C}$ for $1 \mathrm{~min}, 45^{\circ} \mathrm{C}$ for $30 \mathrm{~s}$ and $72^{\circ} \mathrm{C}$ for $1 \mathrm{~min}$, with a final extension step of $72^{\circ} \mathrm{C}$ for $5 \mathrm{~min}$. PCR products were quantitatively assessed by electrophoresis on a $2 \%$ agarose gel, and visible bands corresponding to the COI fragment size were sequenced in two directions. COI sequencing was done using the Sanger method and performed by Macrogen, Europe (Holland) and by Molecular Ecology Lab at the Estación Biológica de Doñana with bcdF05 and bcdR04 (Dabert et al. 2008).

\section{Data analysis}

\section{Sequence editing and Phylogenetic analyses}

The forward and reverse DNA sequences were edited and manually trimmed to $602 \mathrm{bp}$ using Sequencher 5.2 software. Sequences were aligned using CLUSTALW with default settings (Larkin et al. 2007) in Geneious (Drummond et al. 2009) and deposited in Genbank with the accession This article is protected by copyright. All rights reserved. 
numbers (Submission \# 1775289). The final alignment was visually revised using Mega (Tamura et al. 2013) and comprised 362 sequences including Freyana anatina (GenBank acc. no. GQ864352), as an outgroup taxon.

JModelTest 2 (Darriba et al. 2012) was used to determine the appropriate model of sequence evolution for Bayesian analyses. Mr Bayes version 3.2 (Ronquist et al. 2012) was used to run two parallel analyses each with GTR + G + I as the model of evolution, each consisting of four Markov chains of 4,000,000 generations. Convergence of each analysis was evaluated using Tracer 1.4.1 (Rambaut \& Drummond 2007) to check that ESS values were all greater than 200 (default burn-in).

\section{Barcoding analysis}

\section{Assessing specimen identification success}

To assess barcoding accuracy in specimen identification, we used the genetic distances based on the "best close match" (BCM) method presented by Meier et al. (2006). For the analyses we used the bestCloseMatch function of the R package SPIDER version 1.3-0 (http://spider.r-forge.rproject.org/) (Brown et al. 2012). BCM reports four different identification categories: (1) "correct" when the name of the closest match is the same than the specimen considered. (2) "incorrect" when the name of the closest match is different than the specimen considered. (3) "ambiguous" when more than one species is the closest match and (4) "no id" when no species is found within the given threshold. Thus, we obtained a metric of identification success calculated as the percentage of correct identifications. Following Collins et al. (2012) we considered singletons as a different identification scenario where the only possible identification result is "incorrect" or "no id". Therefore, we reported results with singleton species included and excluded. Finally, we also evaluated the performance of barcode sequences in species identification conducting a barcode gap analysis in BOLD (Ratnasingham \& Hebert 2007).

This article is protected by copyright. All rights reserved. 


\section{Checking threshold confidence}

For threshold calculations, the local minima function of the R package SPIDER was used. It is based on the concept of the barcoding gap, where a dip in the density of genetic distances indicates the transition between intra- and inter-specific distances.

As the identity of the species composition of the library may affect the threshold calculated, we explored whether and how our calculated threshold stabilised across a simulated increasing sample of species from our available library. To do so, for each possible sample size from 1 to 72 (the number of species in our library) we created 1,000 random combinations of different species and calculated (with local minima function) the threshold for each subsample. Moreover, following Collins et al. (2012), we evaluated a range of threshold values for their effect on both the false positive $(\alpha)$ and false negative $(\beta)$ error rates using threshold optimisation function in the SPIDER package. The optimum threshold was defined where cumulative errors were minimised.

\section{Mini-barcodes}

The sliding window function slide Analyses in SPIDER (Brown et al. 2012) was used to determine the shortest informative window best discriminating the feather mite sequences of reference. This function extracts all possible windows (DNA sequences) of a chosen size in a DNA alignment, and performs, for each window, distance measures including the following: (1) proportion of zero nonconspecific distances; (2) number of diagnostic nucleotides; (3) number of zero-length distances and overall mean distance; (4) tree-based measures including the proportion of species that are monophyletic; and (5) the proportion of clades that are identical between the neighbour-joining tree calculated for the window and the tree calculated for the full dataset.

After this, the shortest informative window was selected by considering (following Boyer et al. 2012) the proportion of zero pairwise non-conspecific distances in the matrix, and the proportion of identical clades shared between the neighbour-joining tree derived from the full 602 bp dataset (and those derived from each window). Windows with no zero non-conspecific distances and a proportion of identical clades greater than $85 \%$ for shallow nodes (i.e. nodes tipwards of the median This article is protected by copyright. All rights reserved. 
node depth) were considered as highly informative because they allow accurate specimen identification, and provide a good representation of the tree topology for the full dataset. Windows of 50, 100, 150 and 200 bp were analysed and compared to determine the shortest highly informative window. Then, identification success of each of the four most informative selected windows was also tested by BCM as was done before for total length barcode. Tentative regions for group-specific degenerate primers were explored for the selected mini-barcode, using nucleotide diversity analyses conducted on DNAsp software (Librado \& Rozas 2009).

\section{Primary species delimitation}

The ABGD method (Puillandre et al. 2012) was used with phylogenetic analyses to review the primary species discovery in our groups. This method uses many prior thresholds to propose partitioning of specimens into Primary Species Hypotheses (PSHs) based on the distribution of pairwise genetic distances. In this distribution of pairwise differences between sequences, a gap exists between intraspecific and interspecific diversity. This 'barcode gap' can be used as a threshold for delimiting primary species under the consideration that individuals within species are more similar than those between species. The COI sequence alignment was used to compute matrices of pairwise distances using the Kimura 2-parameter (K2P) models with sppDistMatrix function in SPIDER (Brown et al. 2012). Matrices were then used as inputs on the ABGD webpage (http://wwwabi.snv.jussieu.fr/public/abgd/abgdweb.html), using the default settings search on a set of prior minimum genetic distances ranging from 0.001 to 0.1 . Lastly, ABGD output was visually compared with Bayesian phylogeny to check for congruence.

Additionally, we used the Refined Single Linkage (RESL) algorithm of BINs, which performs an initial analysis using a $2.2 \%$ sequence divergence as the minimum distance between clusters (Ratnasingham \& Hebert 2013). BINs splits were also visually compared with ABGD partitions and Bayesian phylogeny to check for congruence.

This article is protected by copyright. All rights reserved. 


\section{Results}

A total of 361 individual mites from 72 species and 12 genera were identified by morphology under the microscope, and their mitochondrial COI region was subsequently sequenced. All nucleotides were translated into functional protein sequences in the correct reading frame, with no stop codons or indels observed in the data. Each species was represented by five individuals on average; 20 species $(27.3 \%)$ had only one individual (i.e. singletons; see other sample statistics in Table 1).

\section{Identification success rates using DNA barcodes}

Using BCM, identification success was usually high (>88\%) when singletons were excluded, and perfect when both the pinnatus group and the singletons were excluded. "ambiguous" identifications increased mainly when the pinnatus group was included in the analyses (Table 2). The same pattern was observed when the barcoding gap analysis in BOLD was used. All species from the pinnatus group always presented nearest neighbour values smaller than the corresponding maximum intraspecific distances. Singletons species always resulted in nearest neighbour distances above the threshold (3.42\%, see below), thus reporting "no id" in the analyses.

\section{Threshold confidence and accuracy}

We obtained a threshold value of $3.42 \%$, which remained the same after threshold optimisation (Fig. 1). Our simulations (see "checking threshold confidence") showed that the threshold stabilised at around 30 mite species, well before reaching the 72 species of our whole data set, thus suggesting that additional sampling would not significantly change the threshold for feather mites of European passerine birds (Fig. 1).

\section{Mini-barcodes}

Sliding window analyses revealed short informative regions from 50 to $200 \mathrm{bp}$. For the four differently sized windows (one per window length), the proportion of zero pairwise non-conspecific distances was 0 . Therefore, the criteria with which to choose the best windows were the proportion This article is protected by copyright. All rights reserved. 
of identical clades shared between the neighbour-joining tree derived from the full length dataset, and those derived from each window. After BCM analyses of all sized best windows, a $200 \mathrm{bp}$ window (located from 295 to $495 \mathrm{bp}$ in our alignment) was the only mini-barcode to obtain exactly the same identification success as the total length barcode. Moreover, this region was surrounded by conserved regions (Fig. 2), thus being potentially useful to design group-specific degenerate primers.

\section{Integrative taxonomy}

DNA barcoding was robust when comparing feather mites of the same species sampled at distant locations (Russia vs Spain), or the same mite species from different bird hosts (Fig. 3). However, our phylogenetic, RESL and ABGD analyses showed a strong genetic structure of two clusters within three Proctophyllodes species: P. musicus, P. stylifer and P. clavatus. In two of these species, clusters within mite species occurred in different but closely-related bird species: Turdus merula and Turdus philomelos on P. musicus (Fig. 3, 4a, Suppl. Fig. S1), and Parus major and Cyanistes caeruleus on P. stylifer (Fig. 3, Suppl. Fig. S1). A similar situation occurred in $P$. clavatus, with a cluster with a single individual found on Acrocephalus schoenobaenus, while the rest of the P. clavatus were found on Sylvia borin. In this case, the individual on A. schoenobaenus was even closer to Proctophyllodes cetti than to the other P. clavatus (Fig. 3, Suppl. Fig. S1). In all three cases, evidence thus suggests that these may be morphologically cryptic mite species living on different (but closely related) bird hosts.

Moreover, our phylogenetic analyses supports the hypothesis that three previously undescribed mite species, recognised by morphology (Mironov pers. obs.), do belong to distinct species, because they show well-isolated clusters in our phylogeny. Two species (from the genera Proctophyllodes and Mesalgoides) were from the red crossbill, Loxia curvirostra, and one from the genus Dolichodectes was hosted on the melodious warbler Hippolais polyglotta (Suppl. Fig. S1, e.g. Fig. 4b ）.

This article is protected by copyright. All rights reserved. 


\section{Discussion}

Here we found a high identification success $(100 \%$ without singletons and the conflictive pinnatus group) using BCM (Meier et al. 2006) for our feather mite library, as previously reported in other arthropod barcoding studies (Virgilio et al. 2010). Contrary to other DNA barcoding studies, in which COI showed high genetic structure between populations within species (Tavares et al. 2011), our results showed high robustness with no geographic genetic structure for our marker, despite the fact that we sequenced the same feather mite species from distant populations of European passerines and the same mite species inhabiting different bird hosts. Previous studies using COI in taxonomical studies of particular feather mite species have reported low intraspecific and higher interspecific genetic distances (Dabert et al. 2008; Dabert et al. 2011; Jinbo et al. 2011; Glowska et al. 2014) suggesting its usefulness for species identification. Here we extend current information providing the largest library of barcodes for feather mites, and our analyses of this library confirm that the COI region is useful for species identification in this group.

Most of the current popular massive parallel sequencing tools (Illumina, Ion Torrent, etc.) have important benefits but also some constraints, such as the limited length of the sequences (Mardis 2011). In this context, mini-barcodes have been presented as a good option for specimen identification in DNA barcoding (Meusnier et al. 2008). In this work, as reported for fish and butterflies (Hajibabaei et al. 2006), we obtained the same identification success with a short region of $200 \mathrm{bp}$ and present it as a tentative mini-barcode region for feather mites. Thus, at least for feather mite species identification, mini-barcodes may be a useful tool.

Choosing appropriate thresholds that can separate species is one of the main challenges and concerns for DNA barcoding studies (Ferguson 2002). This is the basis of important criticisms of barcoding methods, which state that single-gene thresholds for species discovery can result in substantial errors in detecting new species with recent divergence times. Our innovative approach to the assessment of the threshold stability within a barcoding library may help discern when a

This article is protected by copyright. All rights reserved. 
threshold is usable for a certain group. It may be considered that the early stabilisation confers a measure of confidence in the calculated threshold for a particular sampled group. In our library, we achieved a high threshold stabilisation at a level of 30 species ( $<50 \%$ of total library). Moreover, species composition had a small impact on the final threshold obtained. This threshold was $3.14 \%$, interestingly close to the $3 \%$ commonly used in barcoding literature (Hebert et al. 2003). Nevertheless, it is important to note that for threshold calculations we used the local minima function of the R package SPIDER (Brown et al. 2012). This is based on the concept of the barcoding gap, which has been proven to be very effective in some groups (as reported here for feather mites) but not in others (Čandek \& Kuntner 2014). Therefore, these simulations may be sensitive to the same benefits (easy to calculate, easy to interpret, and very repeatable among different groups) and problems (mainly overlaps between intra- and inter-distances in some groups) as the barcoding gap approach (Wiemers \& Fiedler 2007; Čandek \& Kuntner 2014).

The pinnatus group is composed of species highly similar in morphology, and is the most diverse species group in the Proctophyllodes genus (Atyeo \& Braasch 1966; Mironov 2012), thus suggesting a recent and rapid diversification. Our analyses confirmed previous suspicions of taxonomic issues within this group, thus encouraging further additions of new markers and integrated taxonomic approaches, likely leading to a reconsideration of current taxonomic descriptions, and hopefully identification improvements thanks to a multilocus barcoding approach (Dupuis et al. 2012).

The tree inferred from barcoding data (Suppl. Fig. S1) confirmed most of the taxonomies of the relationships of the investigated taxa. The barcoding served as most precise tool for revealing relationships of feather mites at specific and generic levels. This method allowed the clear differentiation of most mite species. It is important to note that these data revealed the (genetic) homogeneity of a mite population of a particular species associated with a particular passerine species within the limits of Europe. On the other hand, these data allowed the detection of

This article is protected by copyright. All rights reserved. 
supposedly cryptic species inhabiting different hosts in the same territory.

With respect to species discovery, we also used an integrative taxonomy approach, with a single-gene analysis from 'DNA barcoding' and a morphological study to determine species hypotheses (Schlick-Steiner et al. 2010). The single-gene data set was analysed with bioinformatic species delimitation tools, such as ABGD or RESL and contrasted with phylogenetic trees (Puillandre et al. 2012; Ratnasingham \& Hebert 2013; Roy et al. 2014). This was useful to confirm the existence of three undescribed species and to discover three likely cases of cryptic species within three morphologically recognised Proctophyllodes species (P. musicus, P. stylifer, and P. clavatus), each associated with a pair of closely-related host species. Interestingly, one of these cases (P. stylifer) was also reported in an independent study by Dabert et al. (2005), thus giving further support to the hypothesis that $P$. stylifer may be composed of at least two cryptic species. In P. clavatus, a cluster with the single mite individual sampled from Acrocephalus shoenobaenus is clearly distant from the rest of the P. clavatus mites sampled from Sylvia borin hosts, but is distinctly closer to $P$.cetti sequences. $P$. clavatus and $P$. cetti show very similar morphology. Association of $P$. clavatus with A. schoenobaenus is not accidental, as it was previously recorded by other authors (Atyeo \& Braasch 1966). All of these cases of potentially cryptic species require further study.

Acknowledgments: Funding was provided by the Ministry of Economy and Competitiveness (Ramón y Cajal research contract RYC-2009-03967 to RJ and research project CGL2011-24466 to RJ). JD was also supported by the Ministry of Economy and Competitiveness (SVP-2013-067939). SV was supported for this study by the Russian Foundation for Basic Research (Grant no. 13-0400608a). The authors thank three anonymous reviewers for suggesting improvements to earlier version of the manuscript. Special thanks to: Miroslawa Dabert for her advice on lab protocols; Rupert A. Collins for his recommendations on the barcoding analysis; Nicolas Puillandre for advice and instructions on ABGD and barcoding interpretation of our results. Francisco Jesus Ruiz Ruano

This article is protected by copyright. All rights reserved. 
for his help with phylogenetic analyses; and Carolina Osuna for her advice and phylogenetic tree illustrations. We thank Alberto Alvarez, Leandro Meléndez, Marc Llobet, Pepe Ayala, RaülAymí, Pere Josa Anguera and Rafael Sanchez for the samples provided.

\section{References}

Atyeo WT, Braasch NL (1966) The feather mite genus Proctophyllodes (Sarcoptiformes :Proctophyllodidae). Bulletin of the University of Nebraska State Museum, 5, 1-354.

Besansky NJ, Severson DW, Ferdig MT (2003) DNA barcoding of parasites and invertebrate disease vectors: what you don't know can hurt you. Trends in Parasitology, 19, 545-546.

Blanco G, Tella JL, Potti J, Baz A (2001) Feather mites on birds: costs of parasitism or conditional outcomes? Journal of Avian Biology, 32, 271-274.

Boyer S, Brown SD, Collins RA, Cruickshank RH, Lefort MC, Malumbres-Olarte J, Wratten SD (2012) Sliding window analyses for optimal selection of mini-barcodes, and application to 454-pyrosequencing for specimen identification from degraded DNA. PloS ONE, 7, e38215.

Brown SDJ, Collins RA, Cruickshank RH, Lefort MC, Malumbres-Olarte J, Wratten SD (2012) Sliding Window Analyses for Optimal Selection of Mini-Barcodes, and Application to 454Pyrosequencing for Specimen Identification from Degraded DNA. PLoS ONE, 7, e38215.

Brown SD, Collins RA, Boyer S, Lefort MC, Malumbre-Olarte J, Vink, CJ, and Cruickshank RH (2012) Spider: An R package for the analysis of species identity and evolution, with particular reference to DNA barcoding. Molecular Ecology Resources, 12, 562-565.

Čandek K, Kuntner M (2014) DNA barcoding gap: reliable species identification over morphological and geographical scales. Molecular Ecology Resources.

Collins RA, Armstrong KF, Meier R, Yi Y, Brown SDJ, Cruickshank RH, Keeling S, Johnston C (2012) Barcoding and Border Biosecurity: Identifying Cyprinid Fishes in the Aquarium Trade. PLoS ONE, 7, e28381.

This article is protected by copyright. All rights reserved. 
Collins RA, Cruickshank RH (2013) The seven deadly sins of DNA barcoding. Molecular Ecology Resources, 13, 969-975.

Dabert M, Solarczyk P, Badek A, Dabert J (2005) Taxonomic status of the oligoxenous feather mite species: are we dealing with species in statu nascendi? Phytophaga, 14, 425-431.

Dabert J, Ehrnsberger R, Dabert M (2008) Glaucalges tytonis sp n.(Analgoidea, Xolalgidae) from the barn owl Tytoalba (Strigiformes, Tytonidae): compiling morphology with DNA barcode data for taxon descriptions in mites (Acari). Zootaxa, 1719, 41-52.

Dabert, M, Bigos A, \& Witalinski W (2011). DNA barcoding reveals andropolymorphism in Aclerogamasus species (Acari: Parasitidae). Zootaxa, 3015, 13-20.

Darriba D, Taboada GL, Doallo R, Posada D (2012) jModelTest 2: more models, new heuristics and parallel computing. Nature Methods, 9, 772-772.

Drummond AJ, Ashton B, Cheung M, Heled J, Kearse M, Moir R, et al. (2009) Geneious v4. 7. Biomatters, Ltd., Auckland, New Zealand.

Dubinin VB (1951) Feather mites (Analgesoidea). Part I. Introduction to their study. Fauna SSSR, Paukoobraznye, 6, 1-363.

Dupuis JR, Roe AD, Sperling FA (2012) Multi-locus species delimitation in closely related animals and fungi: one marker is not enough. Molecular Ecology, 21, 4422-4436.

Ferguson JWH (2002) On the use of genetic divergence for identifying species. Biological Journal of the Linnean Society, 75, 509-516.

Fernández-González S, De la Hera I, Pérez-Rodríguez A, Pérez-Tris J (2013) Divergent host phenotypes create opportunities and constraints on the distribution of two wing-dwelling feather mites. Oikos, 122, 1227-1237.

Figuerola J, Domenech J, Senar JC (2003) Plumage colour is related to ectosymbiont load during moult in the serin, Serinus serinus: an experimental study. Animal Behaviour, 65, 551-557.

This article is protected by copyright. All rights reserved. 
Galván I, Sanz JJ (2006) Feather mite abundance increases with uropygial gland size and plumage yellowness in Great Tits Parus major. Ibis, 148, 687-697.

Galván I, Aguilera E, Atiénzar F, Barba E, Blanco G, Cantó JL, et al. (2012) Feather mites (Acari: Astigmata) and body condition of their avian hosts: a large correlative study. Journal of Avian Biology, 43, 273-279.

Gaud J, Atyeo WT (1996) Feather mites of the World (Acarina, Astigmata): the supraspecific taxa. Annales du Musée royale de l'Afrique centrale, Sciences Zoologiques, 277, 1-193 (Pt. 1, text), 1-436 (Pt. 2, illustrations).

Glowska, E, Dragun-Damian A, Broda L, Dabert J, \& Dabert M (2014) DNA barcodes reveal female dimorphism in syringophilid mites (Actinotrichida: Prostigmata: Cheyletoidea): Stibarokris phoeniconaias and Ciconichenophilus phoeniconaias are conspecific. Folia parasitologica, 61, 272-276.

Hajibabaei M, Janzen DH, Burns JM, Hallwachs W, Hebert PD (2006) DNA barcodes distinguish species of tropical Lepidoptera. Proceedings of the National Academy of Sciences of the United States of America, 103, 968-971.

Hajibabaei M, Singer GAC, Hebert PDN, Hickey DA (2007) DNA barcoding: how it complements taxonomy, molecular phylogenetics and population genetics. Trends in Genetics, 23, 167172.

Hebert PD, Cywinska A, Ball SL (2003) Biological identifications through DNA barcodes. Proceedings of the Royal Society of London. Series B: Biological Sciences, 270, 313-321.

Hebert PD, Ratnasingham S, deWaard JR (2003) Barcoding animal life: cytochrome c oxidase subunit 1 divergences among closely related species. Proceedings of the Royal Society B: Biological Sciences, 270, 96-9.

Hebert PDN, Penton EH, Burns JM, Janzen DH, Hallwachs W (2004) Ten species in one: DNA barcoding reveals cryptic species in the neotropical skipper butterfly Astraptes fulgerator. This article is protected by copyright. All rights reserved. 
Proceedings of the National Academy of Sciences of the United States of America, 101, $14812-14817$.

Huelsenbeck JP, Ronquist F, Nielsen R, Bollback JP (2001) Bayesian inference of phylogeny and its impact on evolutionary biology. Science, 294, 2310-2314.

Jinbo U, Kato T, Ito M (2011) Current progress in DNA barcoding and future implications for entomology. Entomological Science, 14, 107-124.

Krantz G, Walter D, editors (2009) A manual of acarology.3rd edition. Lubbock: Texas Tech University Press.

Larkin MA, Blackshields G, Brown NP, Chenna R, McGettigan PA, McWilliam H, Valentin F, Wallace IM, Wilm A, Lopez R (2007) Clustal W and Clustal X version 2.0. Bioinformatics, 23, 2947-2948.

Librado P, Rozas J (2009) DnaSP v5: a software for comprehensive analysis of DNA polymorphism data. Bioinformatics, 25, 1451-1452.

Mardis ER (2011) A decade's perspective on DNA sequencing technology. Nature, 470, 198-203.

Meier R, Shiyang K, Vaidya G, Ng PK (2006) DNA barcoding and taxonomy in Diptera: a tale of high intraspecific variability and low identification success. Systematic Biology, 55, 715728.

Meléndez L, Laiolo P, Mironov S, García M, Magaña O, Jovani R (2014) Climate-Driven Variation in the Intensity of a Host-Symbiont Animal Interaction along a Broad Elevation Gradient. PloS ONE, 9, e101942.

Meusnier I, Singer GA, Landry JF, Hickey DA, Hebert PD, Hajibabaei M (2008) A universal DNA mini-barcode for biodiversity analysis. BMC Genomics, 9, 214.

Meyer CP, Paulay G (2005) DNA barcoding: error rates based on comprehensive sampling. PLoS Biology, 3, e422.

This article is protected by copyright. All rights reserved. 
Mironov S (1996) Feather mites of the north-west of Russia. Parazitologiya, 30, 521-539. [In

Russian]

Mironov S, Wauthy G (2011) Phylogeny and host-parasite associations of feather mites of the Pteroherpus generic group (Astigmata: Pteronyssidae). In: M. Sabelis and J. Bruin (Eds.), Trends in Acarology (Proceedings of XIIth International Congress of Acarology, Amsterdam, 27 August - 2 September 2006), 23-30.

Mironov S, Dabert J, Dabert M (2012) A new feather mite species of the genus Proctophyllodes Robin, 1877 (Astigmata: Proctophyllodidae) from the Long-tailed Tit Aegithalos caudatus (Passeriformes: Aegithalidae)—morphological description with DNA barcode data. Zootaxa, 3253, 54-61.

Moritz C, Cicero C (2004) DNA barcoding: promise and pitfalls. PLoS Biology, 2, e354.

Proctor HC (2003) Feather mites (Acari: Astigmata): Ecology, Behavior, and Evolution. Annual Review of Entomology, 48, 185-209.

Proctor HC, Owens I (2000) Mites and birds: diversity, parasitism and coevolution. Trends in Ecology and Evolution, 15, 358-364.

Puillandre N, Lambert A, Brouillet S, Achaz G (2012) ABGD, Automatic Barcode Gap Discovery for primary species delimitation. Molecular Ecology, 21, 1864-1877.

Rambaut A, Drummond AJ (2007) Tracer v1. 4.

Ratnasingham S, Hebert PD (2007) BOLD: The Barcode of Life Data System (http://www. barcodinglife. Org). Molecular Ecology Notes, 7, 355-364.

Ratnasingham S, Hebert PD (2013) A DNA-based registry for all animal species: The Barcode Index Number (BIN) System. PLoS One, 8.

Ronquist F, Teslenko M, van der Mark P, Ayres DL, Darling A, Höhna S, Larget B, Liu L, Suchard MA, Huelsenbeck JP (2012) MrBayes 3.2: efficient Bayesian phylogenetic inference and

This article is protected by copyright. All rights reserved. 
model choice across a large model space. Systematic Biology, 61, 539-542.

Roy V, Constantino R, Chassany V, Giusti-Miller S, Diouf M, Mora P, Harry M. (2014) Species delimitation and phylogeny in the genus Nasutitermes (Termitidae:Nasutitermitinae) in French Guiana. Molecular Ecology, 23, 902-920.

Santana FJ (1976) A review of the genus Trouessartia (Analgoidea: Alloptidae). Journal of Medical Entomology, 1, 1-128.

Savolainen V, Cowan RS, Vogler AP, Roderick GK, Lane R (2005) Towards writing the encyclopaedia of life: an introduction to DNA barcoding. Philosophical Transactions of the Royal Society B: Biological Sciences, 360, 1805-1811.

Schlick-Steiner BC, Steiner FM, Seifert B, Stauffer C, Christian E, Crozier RH (2010) Integrative taxonomy: a multisource approach to exploring biodiversity. Annual Review of Entomology, $55,421-438$.

Smith MA, Woodley NE, Janzen DH, Hallwachs W, Hebert PDN (2006) DNA barcodes reveal cryptic host-specificity within the presumed polyphagous members of a genus of parasitoid flies (Diptera: Tachinidae). Proceedings of the National Academy of Sciences of the United States of America, 103, 3657-3662.

Sundquist A, Ronaghi M, Tang H, Pevzner P, Batzoglou S (2007) Whole-genome sequencing and assembly with high-throughput, short-read technologies. PloS ONE, 2, e484.

Tavares ES, Gonçalves P, Miyaki CY, Baker AJ (2011) DNA barcode detects high genetic structure within Neotropical bird species. PloS ONE, 6, e28543.

Tamura K, Stecher G, Peterson D, Filipski A, Kumar S (2013) MEGA6: molecular evolutionary genetics analysis version 6.0. Molecular Biology and Evolution, 30, 2725-2729.

Truett GE, Heeger P, Mynatt RL, Truett AA, Walker JA, Warman ML (2000) Preparation of PCRquality mouse genomic DNA with hot sodium hydroxide and tris (HotSHOT).

This article is protected by copyright. All rights reserved. 
Biotechniques, 29, 52-54.

Virgilio M, Jordaens K, Breman FC, Backeljau T, De Meyer M. (2012) Identifying insects with incomplete DNA barcode libraries, African Fruit flies (Diptera: Tephritidae) as a test case. PloS ONE, 7, e31581.

Wiemers M, Fiedler K (2007) Does the DNA barcoding gap exist?-a case study in blue butterflies (Lepidoptera: Lycaenidae). Frontiers in Zoology, 4, 1-16.

\section{Data Accessibility}

All sequences have been deposited in GenBank and accession numbers for the barcodes, specimens and collection data, are available within the 'Feather mites of European passerines project file (FMEP) in BOLD (http://www.barcodinglife.org), DOI: 10.5883/DS-771988.

Sequence alignment deposited in Dryad: DOI:10.5061/dryad.34702

Phylogenetic data: TreeBASE Study ID S16661.

The $\mathrm{R}$ code used for simulation is available on the GitHub repository: https://github.com/JorgeDona/Barcoding.git

\section{Author Contributions}

JD, JD-R, S.M., DS and RJ conceived and designed the study. JD-R, SM, DS and RJ collected samples from the field. JD-R, PB and RJ designed and performed the laboratory work. JD and JD-R analysed the data. JD, JD-R, SM, PB, DS and RJ wrote the manuscript.

This article is protected by copyright. All rights reserved. 
Table 1. Summary of descriptive barcode statistics for feather mite data analysed.

\begin{tabular}{ll}
\hline Individuals & 361 \\
Species & 72 \\
Mean individuals per sp. (range) & $5(1-22)$ \\
Singletons & 20 \\
Genera & 12 \\
Seq. length (bp) & 602 \\
Number of haplotypes & 319 \\
Haplotype gene diversity & 0.998 \\
Mean intraspecific dist. (range, sd) & $2 \%(0-11,2.04)$ \\
Mean smallest interspecific dist. (range, sd) & $9 \%(0-22,4.83)$ \\
\hline
\end{tabular}

Table 2. \% of the different categories (see Methods) of identification success for BCM with different combinations of singletons and pinnatus group included or excluded. The number of specimens used is shown (n)..

\begin{tabular}{lllllll}
\hline Singletons & pinnatus group & Correct & Incorrect & Ambiguous & No id & $\mathrm{n}$ \\
& & & & & & \\
\hline Included & Included & 83 & 3 & 8 & 6 & 361 \\
Excluded & Included & 88 & 4 & 8 & 0 & 342 \\
Included & Excluded & 93 & 0 & 0 & 7 & 300 \\
Excluded & Excluded & 100 & 0 & 0 & 0 & 281
\end{tabular}

This article is protected by copyright. All rights reserved. 
Table 3. Sliding window analysis results. The selected window for each window length is reported. Proportion of identical clades shared between the neighbour-joining tree derived from the full length datasets, and those derived from each window.

\begin{tabular}{lll}
\hline $\begin{array}{l}\text { Window length } \\
\text { (bp) }\end{array}$ & $\begin{array}{l}\text { Window location } \\
\text { (first nucleotide) }\end{array}$ & $\begin{array}{l}\text { Proportion of } \\
\text { identical clades } \\
\text { shared }\end{array}$ \\
\hline 50 & 259 & 0.94 \\
100 & 286 & 0.96 \\
150 & 283 & 0.96 \\
200 & 295 & 0.97 \\
\hline
\end{tabular}

\section{Figure Legends}

Figure 1. Selected threshold after checking confidence in two ways. (a) Taxon sampling effect upon threshold calculation. Loess fit line with confidence limits is shown. (b) Shows cumulative error and threshold optimisation. Error rates summed across a range of distance thresholds from $0,1-8 \%$ in $0.1 \%$ increments.

Figure 2. Distribution of substitutions, measured as nucleotide diversity $(\pi)$, in the alignment. Window length $=20$ sites. Dashed squares represent low nucleotide diversity regions. Note that the central low diversity region is close to the starting position of the best windows shown in Table 3 .

Figure 3. Bayesian phylogeny for the 361 individual mites of the 72 feather mite species in this study based on COI. Each colour represents a different species according to morphological identification. The large square shows the pinnatus group, where different species occur within the same clusters; this does not occur in the rest of the phylogeny (despite that similar colours may suggest so). The large circle and triangle indicate Proctophyllodes clavatus and P. stylifer, respectively. Filled dots represent individuals from Russia. Small symbols show bird species identity (same arbitrary host symbols are used for different mite species) when a species of mite This article is protected by copyright. All rights reserved. 
was sampled in more than one bird species (when a mite species was found in a single bird species no symbol was used).

Figure 4. Two examples of insights from the integrative taxonomic approach (see Fig. 3 for the relative position of these examples within the larger phylogeny). (a) Tentative cryptic species from Proctophyllodes musicus sampled from close bird species: blackbirds (Turdus merula), top; and song thrushes (Turdus philomelos), bottom. (b) Confirmation of a tentative new species of the genus Dolichodectes previously identified as such by S.M. by morphology. Posterior probabilities values above 0.75 are shown.

Figure 1

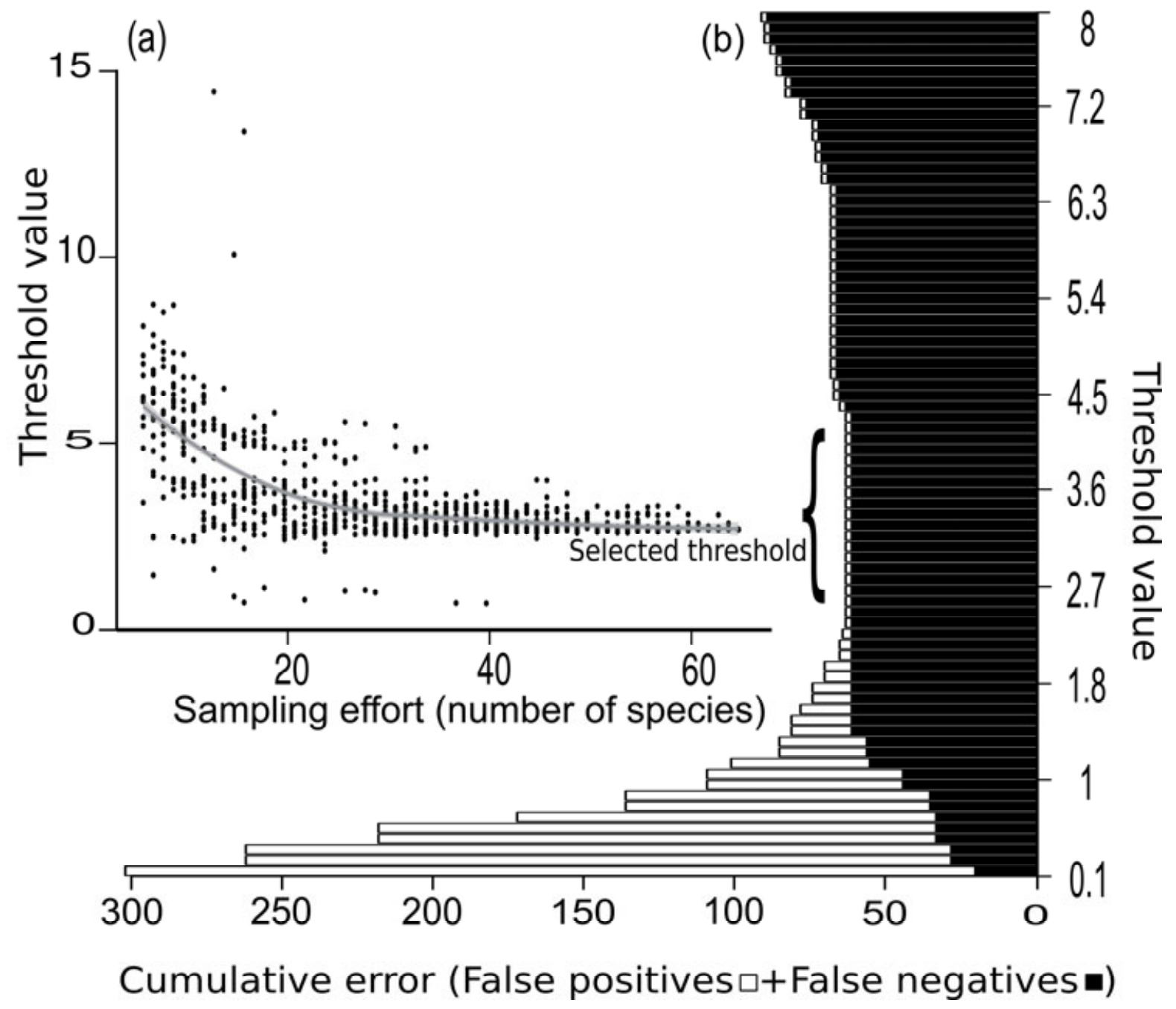

This article is protected by copyright. All rights reserved. 


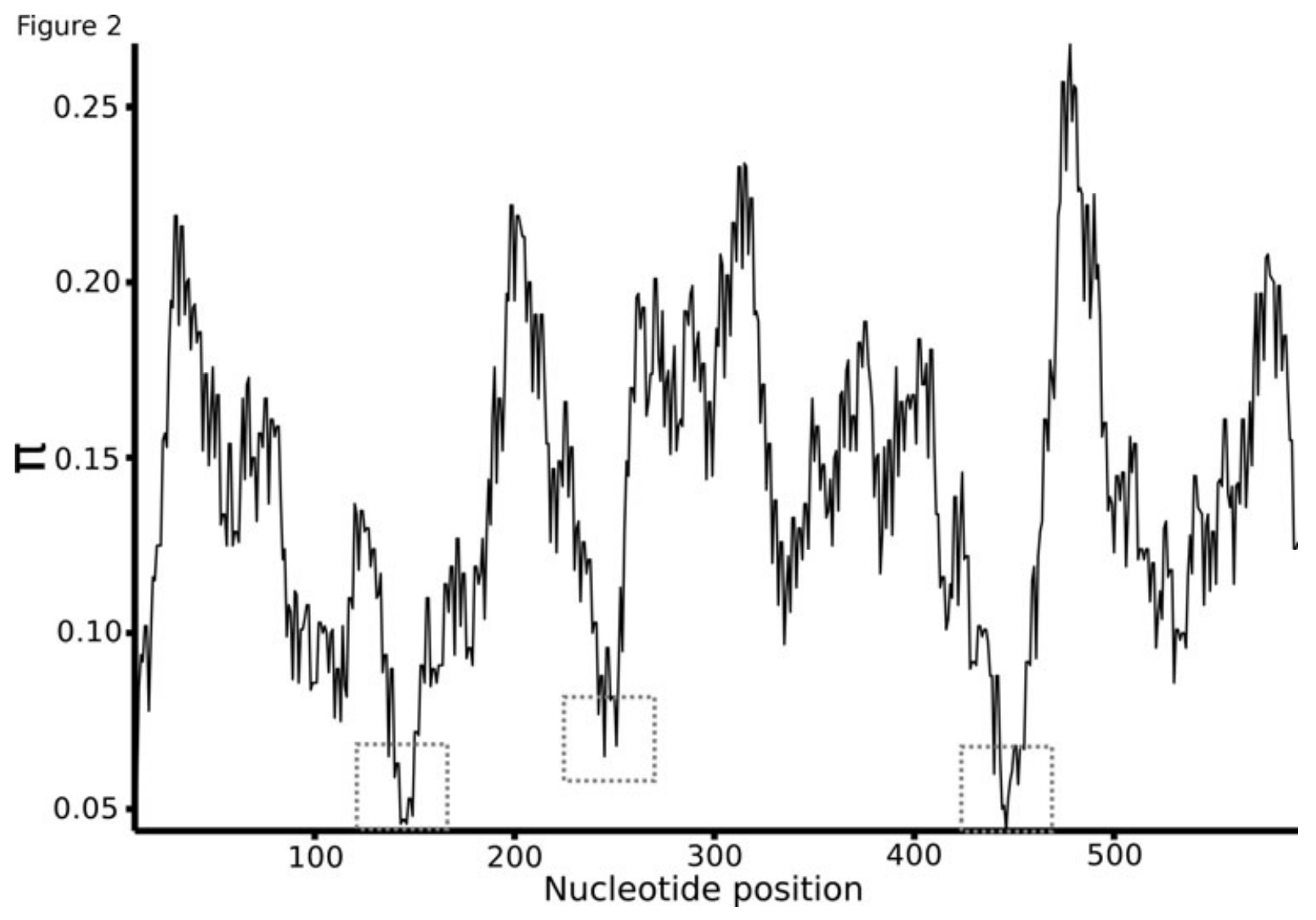

This article is protected by copyright. All rights reserved. 
Figure 3

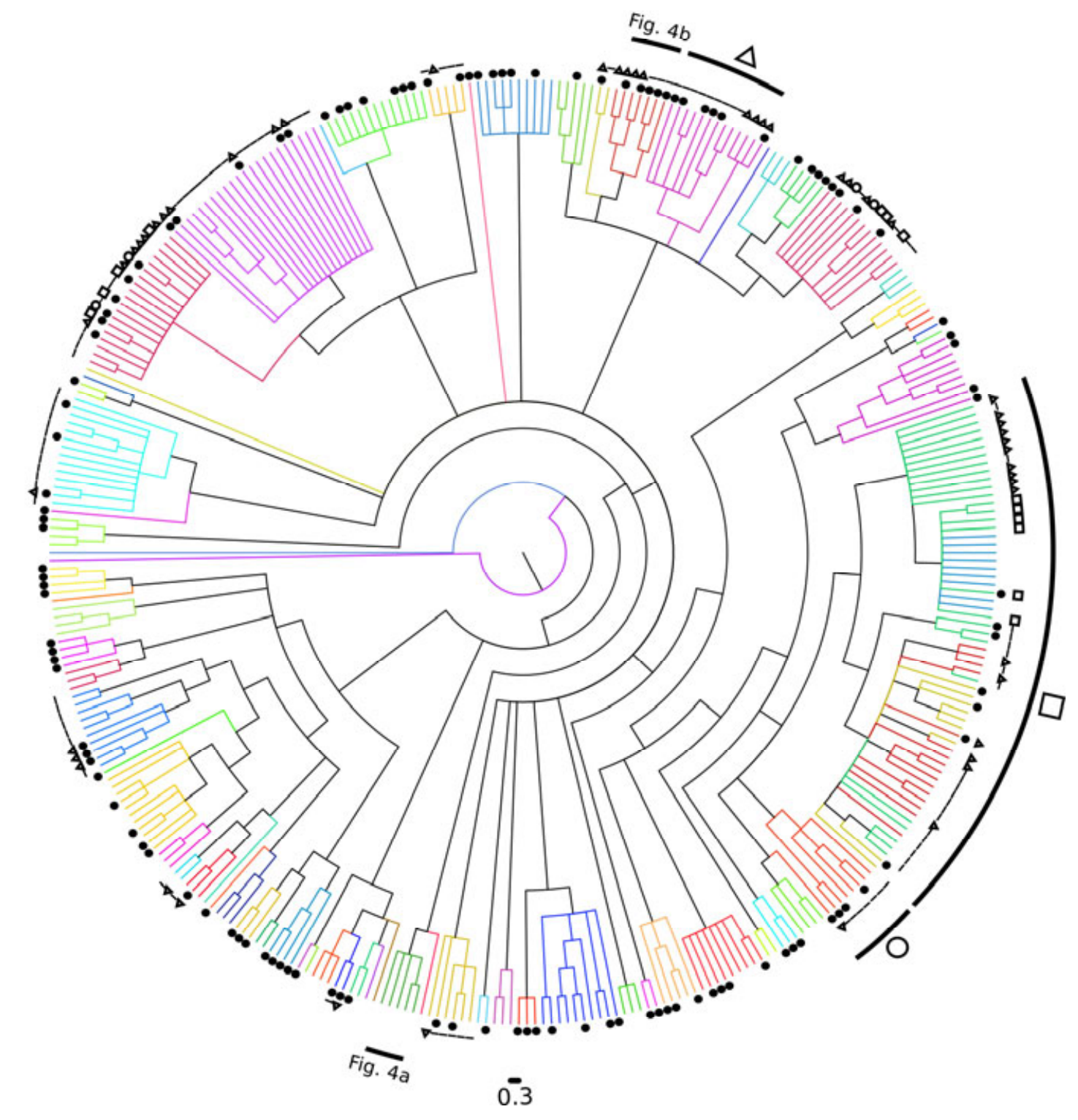

This article is protected by copyright. All rights reserved. 
Figure 4

(a)

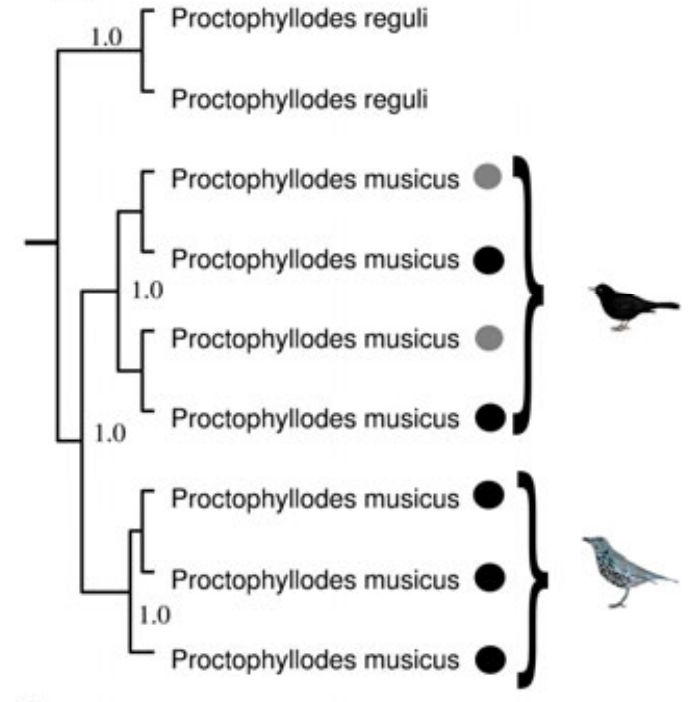

(b)

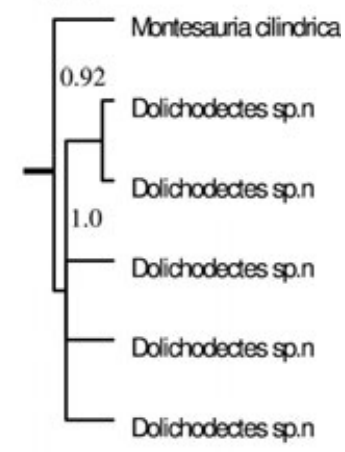

Russia $\quad \overline{2.0}$

This article is protected by copyright. All rights reserved. 